\title{
Designing Laterally Loaded RC Stiffened Plates: Energy Balance Concept
}

\author{
Harvinder Singh \\ Civil Engineering Department, Guru Nanak Dev Engineering College, Punjab, Ludhiana 141006, India \\ Correspondence should be addressed to Harvinder Singh, hvs1221@gmail.com
}

Received 30 July 2012; Accepted 8 October 2012

Academic Editors: X. Li and S. Pantazopoulou

Copyright () 2012 Harvinder Singh. This is an open access article distributed under the Creative Commons Attribution License, which permits unrestricted use, distribution, and reproduction in any medium, provided the original work is properly cited.

Plates are most widely used structural systems to build and/or enclose the space along with some other structural elements, namely, walls, columns, and so forth. in any building. Design procedure for proportioning plates has been recommended in various design codes based upon empirical relations and some factors found on basis of the results of an extensive series of tests and wellestablished performance record of various plate/slab systems constructed in the past. These guidelines have a number of inherent limitations in the form of assumptions, thereby, forcing the designers to proportion the plate system within the domain of these limitations. A procedure to design reinforced concrete stiffened-plates is presented using an energy-balance concept and it can be used for both a single panel as well as multipanel rectangular plate system with any value of aspect ratio, number of panels, and orthotropy. To validate the results from the proposed design procedure, these are compared with the results from well-established literature on the plate analysis and are found to be in good agreement. Working procedure is illustrated with the help of design examples.

\section{Introduction}

Plate stiffened by the internal beams along the one direction or along two orthogonal directions of the plate has been used for many years in bridges and buildings. This type of structural system is efficient, economical, functional, and readily constructible in most of common materials. Moreover, it can be built as a monolithic unit or as a composite system comprising a plate cast in concrete and beams constructed in prestressed concrete, fabricated sections in steel, and so forth. Plates are used almost in every type of structural system to build and/or enclose the space along with some other structural elements such as walls and columns. However, unlike other structural elements, a plate is highly redundant due to the coupling of the internal stress resultants and consequently offers multiple load paths to the applied loading. Because of coupling of internal force resultants, the structural behavior of the plates is highly sensitive to the type, layout of the supporting system, and/or stiffness of the supporting structural member(s). Any change in the physical parameters of the supporting systems will cause a considerable change in the moment-field induced in the plate under given loading conditions.

Various researchers across the globe tried their best to describe the behavior of the plates/slabs of various shapes and edge conditions for different load types. A number of analytical investigations are reported in the literature to describe the behavior of stiffened plates [1-9]. Most of these studies had attempted to formulate expressions based upon elastic theory of plates: boundary element method, finite element method, and so forth, and these expressions are mathematically too cumbersome that these rarely find applications in routine design office jobs.

Empirical relations and some factors have been suggested for apportioning the total static moment among various components of slab-beam system based upon the results of an extensive series of tests and well-established performance record of various slab systems constructed in the past [1017]. These relations and factors have later on formed the basis for the design guidelines recommended by most of the design codes [18-21]. These guidelines have a number of inherent limitations in the form of assumptions, which are 
mandatory to be satisfied by all panels of a plate system for the satisfactory performance, thereby, forcing the designers to proportion the plate system within the domain of these limitations which sometimes fails to satisfy the architectural constraints.

A simple, generalized, and innovative design procedure is suggested for proportioning a reinforced concrete rectangular stiffened plates resting over the simple supports at the outer boundaries in the present paper. A rectangular plate system with any value of aspect ratio and having any number of panels can be designed to withstand a uniform area load acting over the entire top face of the plate. The proposed procedure gives flexibility to the designer to proportion the plate system at any desired strength level of the stiffening beams and the plate can be designed to meet the required strength demand of the plate system and vice versa. The proposed procedure can also be used for a single panel plates as well as multi panel plate system. An attempt has been made to remove the inherent limitations of design procedures recommended by various design codes vis-à-vis constraint on the number of panels, aspect ratio, beam-stiffness ratio, and so forth.

\section{Research Significance}

Numbers of design approaches are available in the published literature and design guidelines. Most of these guidelines have been suggested based upon the empirical results and performance studies of number of plates and slabs cast in the past, thereby possessing a number of inherent limitations in the form of assumptions, and so forth. The proposed analytical procedure gives flexibility to the designer to proportion the single panel or multi panel plate systems at any desired strength level of the stiffening beams and the plate can be designed to meet the required strength demand of the plate system and vice versa. The authors believe that this analytical approach is carried out for the first time and will supplement the design guidelines recommended by various design codes and offer a way to economize the plate system.

\section{Formulation of Design Equations}

Design equations aim to provide a quick estimate of the strength and stiffness requirement for any structural system to enable it to perform satisfactorily during its intended design life. These can be derived by any procedure satisfying the conditions of equilibrium, geometric compatibility, and yield criterion applicable for the system and, simultaneously, these must meet the code requirements of strength and serviceability. Energy balance of the system can be used very conveniently to ensure its equilibrium under a given set of loading and provide a collapse load of the system. The collapse load of any structural system is characterized by a bending moment distribution that satisfies the equilibrium and mechanism conditions along with an applicable yield criterion and there exists only one load factor at collapse that satisfies all these conditions simultaneously. The value of the load factor can be determined uniquely using the minimum and the maximum principles of the limit analysis. According to these principles, the collapse load factor for any structural system is the minimum load factor that has been obtained by fulfilling the equilibrium condition for all possible collapse mechanisms of the system, and it will be the maximum load factor if it has been calculated by considering all those bending moment distributions that satisfy the equilibrium and yield conditions. Therefore, these two conditions will give the lower and the upper bound to the true value of the load factor of a structural system. The true value of a load factor can be achieved by satisfying all these conditions simultaneously. The value of this load factor increases or at least remains the same with the addition of any restraint, whether internal or external, in the structural system and it would reduce with the removal of restraint. This condition can be used very conveniently for predicting the collapse load of a plate system restrained on its all four sides by reducing it into a plate resting over the simple supports on its outer boundaries. Then, it can be suitably reinforced on its top face near the continuous outer edges to resist at least cracking moment without lowering the minimum desirable load factor.

A rectangular reinforced concrete plate adequately restrained on its outer boundary always fails by the formation of a collapse mechanism and possesses a unique collapse mechanism at ultimate state similar to the fingerprint of a living creature. It depends upon the type of edge constraint, loading, and other plate constants, namely, orthotropy, aspect ratio, and geometrical shape, thereby, making the structural behavior of the plate highly sensitive to the type and position of support and/or strength and stiffness of the supporting structural members at its boundary. Any change in the physical parameters of these supporting systems will cause a considerable change in the moment-field induced in the laterally loaded plates. Removal of any supporting member at the outer boundary and/or addition of any flexural member to satisfy the serviceability criterion of the applicable design codes or for economical reasons and so forth will alter the possible collapse mechanism and the corresponding collapse load of the plate system significantly.

The nature and type of the collapse mechanism in case of a plate internally stiffened by equally spaced stiffeners depend greatly upon the strength and stiffness of the internal stiffening beams in addition to other plate constants. If the stiffening beams are strong and stiff enough, these do not allow the yield lines developed in the plate to cross through into the adjacent panels and, consequently, the plate fails with the formation of a yield line pattern, locally and simultaneously, in all panels of the plate under a uniform load acting over the entire face. At this stage, the stiffened plate transforms into a plate system consisting of a number of interconnected smaller plates resting over the internal stiffening beams at the collapse. This type of plate failure mechanism is called as a local collapse mechanism (see Figure 1). Otherwise, if the failure of the plate occurs with the formation of a plastic hinge in the stiffening beams, simultaneously, along with the development of a yield line pattern in the plate, the plate failure mechanism is called a global collapse mechanism. In this case, all the 


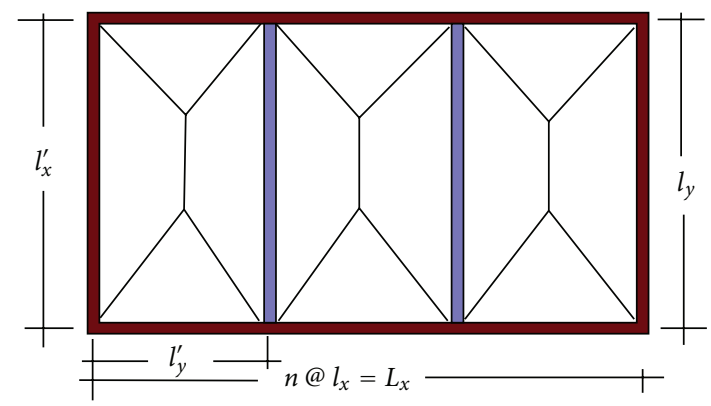

Figure 1: Local Collapse mechanism of the stiffened plate system.

stiffening beams allow the yield line pattern developed in the stiffened plate to pass through it at the point of the plastic hinge as shown in Figure 2. This phenomenon has been experimentally validated by the authors [25]. This mainly happens because of change in the curvature of middle plane of the plate caused by the stiffness of the support system at outer boundary of the plate and/or stiffness of the internal stiffening beams.

Yield lines in any loaded plate always develop along the lines of maximum curvature forming in the plate and the stiffness of the support system whether external or internal is directly responsible for the formation of these lines along the line of maximum curvature in the plate. A highly stiff support or beam causes a sudden change in the curvature across its line and leads to the formation of negative yield lines along its length. A reduction in the beam-stiffness attracts the lines of maximum curvature in the plate toward the internal beams and an increase in the beam stiffness repels these lines away from the beams. At some typical value of the stiffness, line of maximum curvature starts passing through the beam(s), thereby, changing the nature of the collapse mechanism from the local collapse mechanism (highly stiff beam case) to a global collapse mechanism (relatively flexible beam case). The strength of the plate and the stiffening beam $(\mathrm{s})$ in general and strength available along the lines of maximum curvature in particular dictate the collapse load of the stiffened plate system and there exists a coupling between the stiffness and strength of the plate system. Any change in one parameter has a significant effect on the other.

At collapse, the stiffening beam allows the yield line developed in the plate to pass through it, at the point of a plastic hinge, only if the depth of beam is kept less than span/10 for a plate system resting over simple edge at the outer boundary [25]. Otherwise, it starts producing negative yield lines along its length at the loaded face of the stiffened plate. The internal stiffening beams causing the failure of the plate system in a local collapse mechanism are called nonshallow beams and the beams causing the plate failure in a global collapse mechanism are termed shallow beams [25]. Alternatively, the shape of the complete collapse mechanism of a rectangular plate failing in the global collapse mechanism or in the local collapse mechanism can

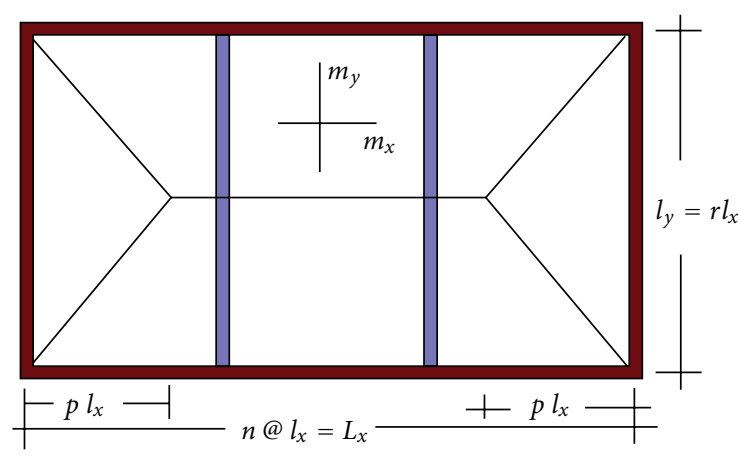

FIGURE 2: Schematic diagram of the model showing global collapse mechanism.

be derived by considering the laws of mechanics of rigid bodies and the theorems postulated by researchers [26-29].

The objective of this formulation is to develop a design procedure that can be used for proportioning a plate system at any desirable strength level of stiffening beams and determines the minimum beam strength level that would ensure the prevention of a local collapse failure in the plate system. Plates designed in the global failure mechanism are relatively more economical in comparison to plates designed for a local collapse mode. In the former case, there is no need to provide any reinforcement at the top face of the plate normal to the internal stiffening beams while it is mandatory to use this reinforcement in the latter case as negative yield line always forms at the top face of the plate due to sudden change in the curvature across the internal stiff beams. Alternatively, a plate system can be made to sustain the load in the local or the global collapse mode by a suitable selection of the strength and/or the stiffness level of the internal stiffening beams or other plate constants.

The plate system is assumed to be resting over the rigid outer boundaries. The aspect ratio of the plate system is $r$ $\left(=l_{y} / L_{x}\right)$. The plate has been stiffened by the number $(n-1)$ of equally spaced stiffening beams, thereby, dividing the plate system into number $(n)$ of panels with panel aspect ratio $r_{p}$ $\left(=l_{y} / l_{x}\right)$. The plate has been reinforced uniformly along the two orthogonal directions with ultimate resisting moment, $m_{u x}$, along the long span $\left(L_{x}\right)$ and with the moment capacity, $m_{u y}$, along the short span $\left(l_{y}\right)$ of the plate with orthotropy, $\mu\left(=m_{u y} / m_{u x}\right)$. The plate is assumed to cast monolithically along with $(n-1)$ number of equally spaced stiffening beams with moment capacity, $m_{b}\left(=\alpha_{b} m_{u x} l_{x}\right)$ each, where $\alpha_{b}$ is the beam strength parameter of the plate system. However, in case of a composite system, the plate and beams should be adequately bonded to each other to prevent the separation at collapse.

The concept of energy balance of a system can be employed very easily to ensure the equilibrium of the plate system at collapse and, consequently, the moment field of the plate system can be derived. Energy stored in the plate system due to a uniform area load acting over the entire top face of the plate and that dissipated along the failure lines of the collapse mechanism can be calculated when the hypothetical collapse mechanism is given an arbitrary 
kinematically admissible displacement field in the direction of the load. The hypothetical collapse mechanisms of the stiffened plate system in both local and global mechanisms are shown in Figures 1 and 2. This has been experimentally validated at various strength and stiffness levels of stiffening beams [25]. As reinforcement has been uniformly distributed at bottom face of the plate, it is very unlikely that a yield criterion would be violated in the plate system. The moment determined by satisfying the equilibrium, the true mechanism of the plate system, and yield criterion will give a true moment field induced in the plate system.

The energy balance of the plate system undergoing a kinematic admissible displacement $(\delta)$ in the direction of the load $(w)$ is given in

$$
\frac{\delta w r_{p} l_{x}^{2}}{6}(3 n-2 p)-2 m_{u x} \delta r_{p}\left[\frac{1}{p}+2 \beta\right]=0 .
$$

In (1), $\beta=\left(\mu n+(n-1) \alpha_{b}\right) / r_{p}^{2}$ is a plate constant that depends upon the panel aspect ratio $\left(r_{p}\right)$ of the plate system, the orthotropy $(\mu)$, and the number of panels $(n)$ into which the plate system has been divided. The variable $(p)$ defines the position of the branching point of the collapse mechanism formed in the plate system under a uniform area load $(w)$ (see Figure 2). Equation (1) can be simplified to a readily usable form, given in [30]

$$
m_{u x}=\left(\frac{3}{A+1}\right)^{2} \frac{w L_{x}^{2}}{24} .
$$

In $(2)$, the variable $(A)$ is the plate-parameter $(=\sqrt{1+3 n \beta})$. The value of the plate-parameter $(A)$ for a single panel plate with aspect ratio of unity becomes equal to two, thereby, giving the plate moment $\left(m_{u x}\right)$ that compares favorably well with the results available in the literature [26] for a single panel square plate with the orthotropy of unity. The exact shape of the collapse mechanism for a reinforced concrete stiffened plate failing in the global collapse mechanism can be determined from (see Figure 2)

$$
p=\frac{3 n}{2(A+1)} \text {. }
$$

The strength demand of the internal stiffening beams of the plate system depends upon the beam strength parameter $\alpha_{b}\left(=m_{b} / m_{u x} l_{x}\right)$ for any given value of the plate moment capacity $\left(m_{u x}\right)$ and the panel length $\left(l_{x}\right)$ of the plate system. It can be calculated by substituting the expression of the plate moment, $m_{u x}$, from (2). This has been given in (4) in terms of the plate-parameter, $A$ as follows:

$$
m_{b}=\left\{\left(\frac{A-1}{A+1}\right) r^{2}-\frac{3 \mu}{(A+1)^{2}}\right\} \frac{w L_{x}^{3}}{(n-1) 4 d} .
$$

Therefore, the design moment field $\left(m_{u x}, m_{u y}=\mu m_{u x}\right.$, and $m_{b}$ ) in the laterally loaded stiffened plate, failing in a global collapse mode can be obtained from (2) and (4) for any valid value of the plate-parameter $(A)$.

The plate system converts into a set of number of smaller isolated rectangular plates if the internal stiffening beams are sufficiently strong and/or stiff; that leads to the formation of a local collapse mechanism. These smaller plates rest over the internal stiffening beams after the formation of the local collapse mechanism. The moment $\left(m_{u x}\right)$ developed in these smaller rectangular plates under uniform area load applied over the entire top face is given in

$$
m_{u y}=\left(\frac{A_{1}-1}{A_{1}+1}\right) \frac{w l_{x}^{2}}{8} .
$$

In (5), $A_{1}=\sqrt{1+3\left(|n r|^{2} / \mu\right)}$ is the plate-parameter for a single panel plate resting over the sufficiently strong and/or stiff beams at its outer boundaries [30].

The relative magnitude of the moment field given by (2) and (5) determines the failure mode of the stiffened plate system. The stiffened plate can be made to fail in the global collapse mechanism or in the local collapse mechanism by controlling the value of the plate-parameter $(A)$. Equations (2) and (5) indicate that there must exist some value of the plate-parameter $(A)$ beyond which failure mode of the stiffened plate transforms from the global collapse to a local collapse mechanism. This value of the plateparameter constitutes the upper limit of plate-parameter $\left(A_{c 2}\right)$ and it has been given in (6). The value of the beam strength parameter of the plate system corresponding to $A_{c 2}$ is called critical beam strength parameter [30] $\left(\alpha_{b c}\right)$ and it has been given is given in (7). This parameter defines the minimum strength of the stiffening beams that leads to the simultaneous formation of the global and local collapse mechanism in the laterally loaded plate system at collapse. One has

$$
\begin{gathered}
A_{c 2}=n \sqrt{3 \mu\left(\frac{A_{1}+1}{A_{1}-1}\right)}-1, \\
\alpha_{b c}=\frac{r^{2}}{3}\left(\frac{n}{n-1}\right)\left[A_{c 2}^{2}-A_{c 1}^{2}\right] .
\end{gathered}
$$

The minimum value of the plate-parameter $(A)$ can be calculated from (8) so that the stiffened plate system must have a positive nonzero stiffening beam moment capacity $\left(m_{b}>0\right)$. Otherwise, the same plate system would start behaving as an ordinary single panel rectangular plate of size $\left(L_{x} \times l_{y}\right)$. The moment field for this type of plate system (with $m_{b}=0$ ) compares favorably well with the results obtained from the well-established formulae of plate/slab analysis. One has

$$
A_{c 1}=\sqrt{\frac{3 \mu}{r^{2}}+1} .
$$

The stiffened plate system can be designed to sustain the load in the global collapse mechanism by selecting the value of the plate-parameter $(A)$ from the range given by the lower limit (8) and the upper limit (6) with the rider that the depth of the stiffening beams must be kept less than span/10. Otherwise, either it would lead to the formation of a local collapse mechanism in the plate system or it would violate the yield criterion in the end panels of the stiffened plate. Equation (7) can also be used to calculate the value 
of the beam strength parameter $\left(\alpha_{b}\right)$ of the plate system by substituting a suitable value of the plate-parameter, $A$, in place of $A_{c 2}$ from the valid range of $A$ values.

\section{Design Procedure}

The design equations derived in the previous section are modified to make the proposed design procedure analogous to that recommended by various design codes and guidelines. The proposed design procedure predicts a moment field being shared between the plate (middle strip as per the code) and the stiffening beams (column strip as per the code) depending upon the value of a plate-parameter $(A)$.

The sum total of the moment field $\left(m_{u x}, m_{u y}\right.$, and $\left.m_{b}\right)$ induced in the panel of the stiffened plate at collapse is given in (9). This total moment in a panel of the plate system is called the panel static moment, PSM. One has

$$
\mathrm{PSM}=m_{b}+m_{u x} l_{x}+m_{u y} l_{y}
$$

Equation (9) can be further simplified by replacing the value of $m_{b}, m_{u y}$ by expressions defined in the previous section. The final expression is given in

$$
\mathrm{PSM}=\left(1+\alpha_{b}+\mu n r\right) m_{u x} \frac{L_{x}}{n} .
$$

In (10), $m_{u x}$ is the moment acting along the span $L_{x}$ of the stiffened plate system. The panel static moment (PSM) in any stiffened plate system, initially, is an unknown factor as it depends upon the internal moment-field induced in the plate system under uniform load $(w)$ acting over the entire top face of the plate system. However, it can very easily be calibrated with the known design parameters of the plate system, namely, uniform area load $(w)$, the short span $\left(l_{y}\right)$, and the long span $\left(L_{x}\right)$. All these known parameters of the plate system can be expressed as a Nichol's moment, NM [31] given in (11). Most of the design codes [18, 20, 21] uses Nichol's moment acting in the panel of the plate system for calculating the middle-strip and the column-strip moments of the plate systems. One has

$$
\mathrm{NM}=\frac{w l_{x} l_{y}^{2}}{8}=\left(\frac{r^{2}}{8 n}\right) w L_{x}^{3}
$$

By combining (10) and (11), a nondimensional factor, $k$, is obtained to convert the Nichol's moment (NM) to the panel static moment (PSM) acting in the stiffened plate. The final expression for this factor is given in

$$
k=\frac{\mathrm{PSM}}{\mathrm{NM}}=\frac{8}{r^{2}}\left(1+\alpha_{b}+\mu n r\right) \frac{m_{u x}}{w L_{x}^{2}} .
$$

Equation (12) can be simplified to a generalized expression given in (13) by substituting the value of the plate moment $\left(m_{u x}\right)$ from $(2)$. One has

$$
k=\frac{3}{[r(A+1)]^{2}}\left(1+\alpha_{b}+\mu n r\right) .
$$

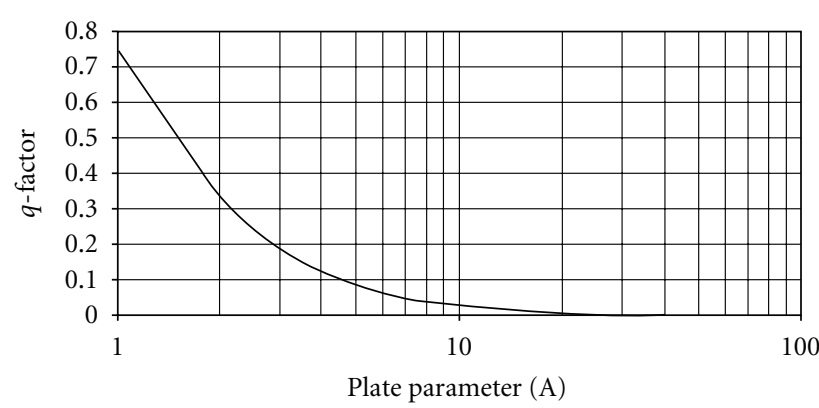

FIgURE 3: Variation of $q$ factor with the plate-parameter $(A)$.

Equation (13) consists of a constant and variable term. These are separated to simplify the design equation as given in

$$
k=q\left[\frac{1+\alpha_{b}+\mu n r}{r^{2}}\right]
$$

The $q$ factor in (14) is a participation factor $(q)$ which is a pure function of the plate-parameter $(A)$. The expression of the participation factor is given in (15) and the variation of this factor with the plate-parameter $(A)$ has been shown in Figure 3. The terms in the bracket are plate constants for a given design constraints of the plate system. One has

$$
q=\left\{\frac{3}{(A+1)^{2}}\right\} \text {. }
$$

A suitable value of the plate-parameter $(A)$ is selected from the valid range defined in (6) and (8) to calculate the participation factor $(q)$. Then, for a given set of plate constants $\left(\mu, n, r\right.$ and $\left.\alpha_{b}\right)$, the $k$ factor can be determined from (14).

The panel static moment (PSM) of the stiffened plate can be determined from the known Nichol's moment (NM) (11) by multiplying it with the $k$ factor (14). The panel static moment (PSM) can be divided in ratio of $1: \alpha_{b}$ : $\mu n r$ to calculate the plate moment, $m_{u x}$, acting over the length $\left(l_{x}\right)$, the stiffening beam-moment, $m_{b}$, and the plate moment, $m_{u y}$, acting over the length $\left(l_{y}\right)$ of the stiffened plate, respectively. These moments can be converted to the moment per unit width of the plate by dividing these values by the corresponding side of the panel.

\section{Design Examples and Validation}

The procedural steps for proportioning the stiffened plates using the proposed design approach and their comparison with the results from well-established literature on the slab/plate analysis are illustrated in following examples.

5.1. Example 1. There is a proposal to construct a reinforced concrete slab over a plan area of $25 \mathrm{~m} \times 15 \mathrm{~m}$ (984.25 in $\times 590.55$ in). Assuming an elastic distribution of moment-field in the plate, suggest a suitable stiffened plate system and determine a design moment field for the 
proposed plate system subjected to a uniform area load of $11 \mathrm{kN} / \mathrm{m}^{2}$ (0.33 psi).

Assuming that $15 \mathrm{~m}$ (590.55 in) length of the plan area is divided into 3 bays of $5 \mathrm{~m}$ (196.85 in) each, and length along $25 \mathrm{~m}$ (984.25 in) of the plan is divided into " $n$ " number of equally spaced bays, and to maintain the ratio of column spacing along the two orthogonal directions equal to 1.25, the value of " $n$ " must be equal to 4 . Therefore, the given plan is divided into 3 bays of $5 \mathrm{~m}$ (196.85 in) each along $15 \mathrm{~m}$ ( $590.55 \mathrm{in}$ ) length and 4 bays of $6.25 \mathrm{~m}$ (246.06 in) each along the $25 \mathrm{~m}$ (984.25 in) length of the area.

The 3-span beam along $15 \mathrm{~m}$ (590.55 in) length can be made to behave as a nonshallow beam by selecting the depth of the beam more than or at the most equal to span/10 (= $0.5 \mathrm{~m}$ (19.68 in)), and providing the same depth of the beam along the other direction of the grid will give a span/depth ratio of 12.5 ( $>10)$ and, therefore, it will behave as a shallow beam [25]. Moreover, the designer has an option to select any suitable value of the depth of the stiffening beams depending upon the architectural constraint, and so forth, satisfying the serviceability criterion of the applicable design guidelines and span/depth ratio of the shallow beams provided along $6.25 \mathrm{~m}$ (246.06 in) lengths.

Therefore, the stiffened plate of overall size $25 \mathrm{~m} \times 15 \mathrm{~m}$ $(984.25 \times 590.55 \mathrm{in})$ consists of a set of four smaller threepanel rectangular plates of size $15 \mathrm{~m} \times 6.25 \mathrm{~m}(590.55 \times 246$. 06 in) each stiffened by a set of internal shallow beams. This stiffened plate is resting over the rigid edges on the outer four sides.

In this case, number of panels, $n=3$, and the plate are subjected to a uniform area load, $w=11 \mathrm{kN} / \mathrm{m}^{2}(0.33 \mathrm{psi})$.

The plate length, $L_{x}=15 \mathrm{~m}$ (590.55 in), and width, $l_{y}=6.25 \mathrm{~m}$ (246.06 in).

Therefore, the aspect ratio of the plate, $r=6.25 / 15=$ 0.417 .

Orthotropy of the plate, $\mu=2.68$ (Assumed) [30].

The lower limit of the plate-parameter, $A_{c 1}=6.878$ (from (8)).

The upper limit of the plate-parameter, $A_{c 2}=16.09$ (from (6)).

The stiffening beams in the plate system would act as shallow-flexible beams only if these have been designed for any value of the plate-parameter $(A)$ lyingwithin the $A_{c 1}$ and $A_{c 2}$. The value of this plate parameter $(A)$ always leads to the formation of a global collapse mechanism in the plate [25]. The value of the participation factor $(q)$ and $k$ factor can be calculated from (14) and (15) as follows:

$$
\begin{aligned}
& q \text { factor }=0.03324 \text { for } A=8.5(\text { from }(15)), \\
& \alpha_{b}=\left(0.417^{2} / 3\right)(3 /(3-1))\left[8.5^{2}-6.8783^{2}\right]=2.168, \\
& k \text { factor }=1.2465(\text { from }(14)), \\
& \text { Nichol's moment }=\left(10 \times 5 \times 6.25^{2}\right) / 8=268.55 \mathrm{kNm} \\
& \left(47.08 \times 10^{6} \mathrm{lb}-\mathrm{in}\right) .
\end{aligned}
$$

Therefore, $\mathrm{PSM}=1.2465 \times 268.55=334.75 \mathrm{kNm}(58.68$ $\times 10^{6} \mathrm{lb}$-in) and this can be divided in the ratio of $1: \alpha_{b}: \mu n r$
$(=1: 2.168: 3.35)$ to determine the plate moment, $m_{u x}$ $\left(=10.27 \mathrm{kNm} / \mathrm{m}\left(49.52 \times 10^{3} \mathrm{lb}\right.\right.$-in $\left.)\right)$, beam moment, $m_{b}$ $\left(=111.34 \mathrm{kNm}\left(19.52 \times 10^{6} \mathrm{lb}\right.\right.$-in $\left.)\right)$ and plate moment, $m_{u y}$ $\left(=27.53 \mathrm{kNm} / \mathrm{m}\left(133.72 \times 10^{3} \mathrm{lb}\right.\right.$-in/in $\left.)\right)$ respectively. The plate can suitably be reinforced at the top face along the length of a 3-span nonshallow beam to control the flexural cracking due to a sudden change in the curvature of the plate under the loading. This top reinforcement can be provided as per relevant provisions of applicable design codes for the corner steel, and it always results in a safe design due to the increase in a load factor of the proposed stiffened plate system at collapse.

5.2. Example 2. Consider a typical rectangular plate of size $20.12 \mathrm{~m} \times 14.32 \mathrm{~m}(792.12 \mathrm{in} \times 563.78 \mathrm{in})$ resting over the nonyielding supports at the outer boundaries is subjected to a uniform area load of $10 \mathrm{kN} / \mathrm{m}^{2}(0.3 \mathrm{psi})$. The plateis divided into four panels of $5.03 \mathrm{~m}$ (198.03 in) each. Determine the moment field in the stiffened plate assuming orthotropy of the plate as 1.482 and compare the results from the analytical model with that obtained from the finite element analysis.

In the given problem, number of panels, $n=4$.

Uniform area load, $w=10 \mathrm{kN} / \mathrm{m}^{2}$ (0.3 psi).

Length of the plate, $L_{x}=20.12 \mathrm{~m}$ (792.12 in) and the plate width, $l_{y}=14.32 \mathrm{~m}$ (563.78 in).

Therefore, aspect ratio of the plate, $r=20.12 / 14.32=$ 0.7135 .

And, the panel length, $l_{x}=5.03 \mathrm{~m}$ (198.03 in).

Orthotropy, $\mu=1.482$ (given).

The lower limit of the plate-parameter, $A_{c 1}=3.1198$ (from (8)).

The upper limit of the plate-parameter, $A_{c 2}=9.763$ (from (6)).

The stiffened plate can be proportioned for any value of the plate-parameter $(A)$ from the valid range, defined by (6) and (8). The moment-field in the stiffened plate under a uniform load of $10 \mathrm{kN} / \mathrm{m} 2(0.3 \mathrm{psi})$ is given in Table 1 and this has been compared with the results from the output from a finite element analysis. In this case, a dimensionless parameter called as moment manipulator, $\lambda$ $\left(=\left(A^{2}-A_{c 1}^{2}\right) /\left(A_{c 2}^{2}-A_{c 1}^{2}\right)\right)$, has been used to define the strength level of the stiffening beams [30].

It is indicated in Table 1 that moment in the stiffening beams reduces with the reduction in the value of moment manipulator $(\lambda)$. Accordingly, supporting beams of comparatively smaller depths are required to provide the requisite flexural strength to the stiffened plate system at low $\lambda$ values and vice versa. Alternatively, the tensile steel in the stiffening can be reduced to provide a matching strength to the moment demand of the stiffened plate system.

In order to validate the proposed design procedure, finite element based software was used to compare the results given in Table 1. In the numerical study, a four-panel rectangular plate was subjected to an out-of-plane uniform area load of intensity, $10 \mathrm{kN} / \mathrm{m}^{2}$ (0.3 psi). Only a linear-elastic analysis 
TABLE 1: Variation of the moment field with the plate parameter (results from the proposed model).

\begin{tabular}{|c|c|c|c|c|c|c|}
\hline Moment manipulator, $\lambda$ & 0 & 0.2 & 0.4 & 0.6 & 0.8 & 1.0 \\
\hline Plate moment, $m_{u x}, \mathrm{kNm} / \mathrm{m}$ & 89.14 & 43.83 & 29.61 & 22.50 & 18.21 & 15.32 \\
\hline$\left(\times 10^{3} \mathrm{lb}-\mathrm{in} / \mathrm{in}\right)$ & $(429.75)$ & $(211.31)$ & $(142.75)$ & $(108.47)$ & $(87.79)$ & $(73.86)$ \\
\hline Stiffening beam moment, $m_{b}, \mathrm{kNm}$ & 0.00 & 700.0 & 944.6 & 1077.0 & 1162.0 & 1221.0 \\
\hline$\left(\times 10^{6} \mathrm{lb}-\right.$ in $)$ & $(0.00)$ & $(122.71)$ & $(165.59)$ & $(188.80)$ & $(203.70)$ & $(214.04)$ \\
\hline
\end{tabular}

TABLE 2: Variation of the moment-field with the beam depth (results from the FEM model).

\begin{tabular}{lcccccc}
\hline Moment-manipulator, $\lambda$ & 0 & 0.2 & 0.4 & 0.6 & 0.8 & 1.0 \\
\hline Span/depth ratio of the beam & 30.00 & 25.00 & 20.79 & 17.31 & 14.41 & 12.00 \\
Plate moment, $m_{u x}, \mathrm{kNm} / \mathrm{m}$ & 93.07 & 47.19 & 35.20 & 25.40 & 19.40 & 15.27 \\
$\left(\times 10^{3} \mathrm{lb}-\mathrm{in} / \mathrm{in}\right)$ & $(448.70)$ & $(227.51)$ & $(169.71)$ & $(122.46)$ & $(93.53)$ & $(73.62)$ \\
Beam moment, $m_{b}, \mathrm{kNm}$ & 0.00 & 765.0 & 930.0 & 1067.0 & 1168.0 & 1232.0 \\
$\left(\times 10^{6} \mathrm{lb}-\right.$ in $)$ & $(0.00)$ & $(134.11)$ & $(163.03)$ & $(187.05)$ & $(204.75)$ & $(215.97)$ \\
\hline
\end{tabular}

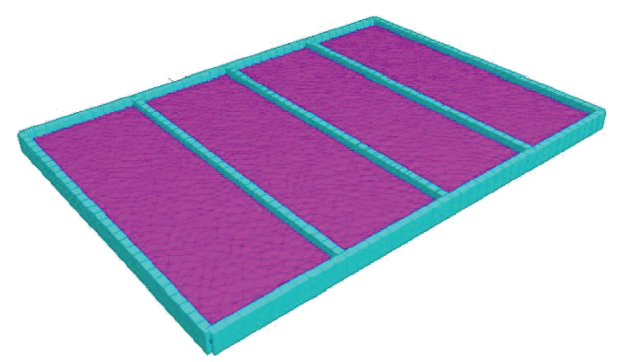

Figure 4: Finite element model showing the meshing of the stiffened plate system.

was performed to determine the moment field induced in the plate system under the given load because the moment-field determined by considering the true collapse mechanism, equilibrium conditions, along with the applicable yield criterion would always predict a true solution and results in this case would be identical with those calculated from the lower-bound analysis. The depth of the stiffening beams in the plate system is taken arbitrarily from a set of number of beam depths examined in the finite element analysis.

Table 2 tabulates the maximum value of moments induced in the stiffened plate under a lateral load of $10 \mathrm{kN} / \mathrm{m}^{2}(0.3 \mathrm{psi})$ along with the corresponding depth of the stiffening beams. The position of the maximum moment in the plate and the stiffening beams is found to be identical in the analytical model and numerical simulation using the finite element software and these moments occurred along the line of hypothetical collapse mechanism. The finite model of the stiffened plate is shown in Figure 4. It is indicated in Tables 1 and 2 that the moment field in the plate system compares favorably well with the results obtained from the finite element analysis. The moment field in both these cases follows exactly the values recommended by the design code [20] for the rectangular slab with discontinuous edges on all four sides. The comparison of the moment field predicted from the proposed design equations with most of the commonly used design equations in the literature and design offices have been given in Table 3.
Table 3 indicates that the results from the proposed design equations compare well with the results from the well-established formulae for the slab/plate analysis as well as the guidelines recommended by design code [20]. It is important to note that the design code requires that only the middle strip, which is three-fourth the width of the entire plate/slab, be reinforced. Therefore, in Table 3, the moment field calculated using the code moment coefficients has been modified to give a moment field acting over the entire width of the slab/plate by reducing it by a factor of 0.75 . The total static moment in the plate turns out to be nearly same in all cases. However, the proposed design equation is simple to use and it can be used for proportioning the stiffened plate system for any arbitrarily chosen plate constant as per the field/design constraints. The thickness of the plate and the stiffening beams can be provided to suit the design constraints vis-à-vis beam-drop restriction, long spans, and so forth by selecting a suitable value of the plate-parameter (A). Most importantly, the proposed method can be used very conveniently to economize the plate system in case of plates requiring minimum tensile steel to satisfy the design code with regards to maximum/minimum rebar spacing. In such situations, designer can opt for suitable rebar spacing as per design code requirement and beams can be proportioned to meet the balance strength demand of the plate system. Moreover, it will define the shape of collapse mechanism of the plate system in routine flow of calculations thereby saving a considerable amount of time that is otherwise get used in determination of the support reactions and so forth from some other supplementary formulae.

\section{Conclusions}

(1) Design equations and a generalized procedure have been suggested for proportioning the reinforced concrete rectangular stiffened plate resting over the simple nonyielding edges on its outer boundary. These equations can be used for the design of both single panel as well as multi panel rectangular plates for any value of aspect ratio, number of panels, and orthotropy. 
TABLE 3: Comparison of the moment-field with the results from the published literature.

\begin{tabular}{|c|c|c|c|c|c|c|}
\hline$\lambda$ & Moment field & $\begin{array}{c}\text { Proposed design } \\
\text { equations }\end{array}$ & Design code [20] & $\begin{array}{l}\text { Upper-bound limit } \\
\text { analysis [22] }\end{array}$ & $\begin{array}{l}\text { Lower-bound limit } \\
\text { analysis [23] }\end{array}$ & $\begin{array}{c}\text { Elastic plate theory } \\
{[24]}\end{array}$ \\
\hline \multirow{4}{*}{0} & $\begin{array}{c}m_{u x}, \mathrm{kNm} / \mathrm{m} \\
\left(\times 10^{3} \mathrm{lb}-\mathrm{in} / \mathrm{in}\right)\end{array}$ & $\begin{array}{c}89.140 \\
(429.75)\end{array}$ & $\begin{array}{c}86.130 \\
(415.24)\end{array}$ & $\begin{array}{c}89.139 \\
(429.75)\end{array}$ & $\begin{array}{c}94.926 \\
(457.65)\end{array}$ & $\begin{array}{c}78.05 \\
(376.29)\end{array}$ \\
\hline & $\begin{array}{l}m_{u y}, \mathrm{kNm} / \mathrm{m} \\
\left(\times 10^{3} \mathrm{lb}-\mathrm{in} / \mathrm{in}\right)\end{array}$ & $\begin{array}{c}132.11 \\
(636.92)\end{array}$ & $\begin{array}{c}131.03 \\
(631.71)\end{array}$ & $\begin{array}{l}132.105 \\
(636.89)\end{array}$ & $\begin{array}{c}140.68 \\
(678.23)\end{array}$ & $\begin{array}{c}152.64 \\
(735.89)\end{array}$ \\
\hline & $\begin{array}{c}m_{b}, \mathrm{kNm} \\
\left(\times 10^{6} \mathrm{lb}-\mathrm{in}\right)\end{array}$ & $\begin{array}{c}0 \\
(0.0)\end{array}$ & $\begin{array}{c}0 \\
(0.0)\end{array}$ & $\begin{array}{c}0 \\
(0.0)\end{array}$ & $\begin{array}{c}0 \\
(0.0)\end{array}$ & $\begin{array}{c}0 \\
(0.0)\end{array}$ \\
\hline & $\begin{array}{l}\text { Total static moment, kNm } \\
\qquad\left(\times 10^{6} \mathrm{lb}-\mathrm{in}\right)\end{array}$ & $\begin{array}{l}3685.31 \\
(646.04) \\
\end{array}$ & $\begin{array}{l}3609.28 \\
(632.71) \\
\end{array}$ & $\begin{array}{l}3685.22 \\
(646.02)\end{array}$ & $\begin{array}{l}3924.45 \\
(687.96) \\
\end{array}$ & $\begin{array}{l}3756.17 \\
(658.46) \\
\end{array}$ \\
\hline \multirow{3}{*}{1} & $\begin{array}{c}m_{u x}, \mathrm{kNm} / \mathrm{m} \\
\left(\times 10^{3} \mathrm{lb}-\mathrm{in} / \mathrm{in}\right)\end{array}$ & $\begin{array}{c}15.32 \\
(73.86)\end{array}$ & & $\begin{array}{l}15.309 \\
(73.81)\end{array}$ & $\begin{array}{l}16.156 \\
(77.89)\end{array}$ & $\begin{array}{c}3.014 \\
(14.53)\end{array}$ \\
\hline & $\begin{array}{c}m_{u y}, \mathrm{kNm} / \mathrm{m} \\
\left(\times 10^{3} \mathrm{lb}-\mathrm{in} / \mathrm{in}\right)\end{array}$ & $\begin{array}{c}22.71 \\
(109.49)\end{array}$ & $\begin{array}{l}\text { Not applicable as } \\
\text { aspect ratio of the } \\
\text { panel exceeds } 2 .\end{array}$ & $\begin{array}{c}22.689 \\
(109.39)\end{array}$ & $\begin{array}{c}23.943 \\
(115.43)\end{array}$ & $\begin{array}{c}23.411 \\
(112.87)\end{array}$ \\
\hline & $\begin{array}{c}m_{b}, \mathrm{kNm} \\
\left(\times 10^{6} \mathrm{lb}-\mathrm{in}\right)\end{array}$ & $\begin{array}{c}1221.0 \\
(214.04)\end{array}$ & & \multicolumn{3}{|c|}{ Expression not available } \\
\hline
\end{tabular}

(2) The results for a single panel plate obtained from the suggested procedure compare favorably well with the values obtained from well-established literature on the yield line theory and other design guidelines.

(3) The results for a stiffened plate system obtained from the suggested procedure compare favorably well with the values obtained from the finite element based software.

(4) Using the suggested procedure, rectangular stiffened plates can be proportioned at any strength level of the stiffening beams. These can be made to behave like a nonyielding edge by keeping the value of the plate-parameter $(A)$ at its upper limit $\left(A_{c 2}\right)$ and the same plate system can be made to act as a single panel plate by selecting the value of the plate-parameter $(A)$ equal to its lower limit $\left(A_{c 1}\right)$.

(5) The plate-parameter $(A)$ can be used very conveniently to control the participation of the plate in the load sharing between the stiffening beams and plate of the stiffened plate. The plate and the stiffening beams will share the moment field $\left(m_{u x}, m_{b}\right.$, and $\left.m_{u y}\right)$ induced in the panel of the stiffened plate in ratio of $1: \alpha_{b}: \mu n r$, respectively.

(6) Expression for $k$ factor is suggested to convert the Nichols moment (NM) into the panel static moment (PSM) that can be distributed among the plate and the stiffening beams in ratio of $1: \alpha_{b}: \mu n r$ to determine the design moment field in the stiffened plate.

\section{List of Symbols}

$w: \quad$ Uniform lateral load

$l_{x}$ : $\quad$ Panel length of the plate

$L_{x}$ : $\quad$ Long span of the plate

$l_{y}: \quad$ Short span of the plate

$r_{p}$ : Aspect ratio of plate-panel

$r$ : $\quad$ Aspect ratio of plate

$n$ : $\quad$ Number of plate panels

$\mu$ : $\quad$ Orthotropy of the plate

$m_{u x}$ : Moment along the long span of the plate

$m_{u y}$ : Moment alongthe short span of the plate

$m_{b}$ : Beam moment

$\alpha_{b}: \quad$ Beam strength parameter

$\alpha_{b c}$ : Critical beamstrength parameter

$\delta: \quad$ Virtual displacement

$\lambda$ : $\quad$ Moment manipulator

$p$ : $\quad$ Branching point of a yield line pattern

$d, e, f$ : Continuity constants

$\beta$ : $\quad$ Plate-beam parameter of plate system

$\beta_{1}$ : $\quad$ Plate constant for single panel

$\beta_{c}$ : $\quad$ Critical plate beam parameter

A: $\quad$ Plate parameter

$A_{1}$ : $\quad$ Plate parameter for single panel

$A_{c 1}$ : $\quad$ Lower limit of plate parameter

$A_{c 2}$ : Upper limit of plate parameter

PSM: Panel static moment

q: $\quad$ Participation factor.

\section{Acknowledgments}

The author wishes to express his gratitude and sincere appreciation to Guru Nanak Dev Engineering College, Ludhiana, and All India Council for Technical Education, New Delhi, for the support and financial help rendered in this research project. 


\section{References}

[1] E. J. Sapountzakis, "Recent advances in the dynamic analysis of stiffened plates-application to concrete or to composite steelconcrete structures," Recent Patents on Engineering, vol. 3, no. 1, pp. 39-59, 2009.

[2] A. W. M. Kok and J. Blaauwendraad, "Shape-orthotropic stressing-bending plate model," Engineering Structures, vol. 30, no. 10, pp. 2884-2892, 2008.

[3] L. Brubak and J. Hellesland, "Strength criteria in semianalytical, large deflection analysis of stiffened plates in local and global bending," Thin-Walled Structures, vol. 46, no. 12, pp. 1382-1390, 2008.

[4] E. J. Sapountzakis and V. G. Mokos, "An improved model for the analysis of plates stiffened by parallel beams with deformable connection," Computers and Structures, vol. 86, no. 23-24, pp. 2166-2181, 2008.

[5] E. J. Sapountzakis and J. T. Katsikadelis, "A new model for slab and beam structures-comparison with other models," Computers and Structures, vol. 80, no. 5-6, pp. 459-470, 2002.

[6] O. K. Bedair, "Analysis of stiffened plates under lateral loading using sequential quadratic programming (SQP)," Computers and Structures, vol. 62, no. 1, pp. 63-80, 1997.

[7] A. R. Kukreti and E. Cheraghi, "Analysis procedure for stiffened plate systems using an energy approach," Computers and Structures, vol. 46, no. 4, pp. 649-657, 1993.

[8] R. B. Schubak, M. D. Olson, and D. L. Anderson, "Rigid-plastic modelling of blast-loaded stiffened plates-part I: one-way stiffened plates," International Journal of Mechanical Sciences, vol. 35, no. 3-4, pp. 289-306, 1993.

[9] D. E. Manolakos and A. G. Mamalis, "Limit analysis for laterally loaded stiffened plates," International Journal of Mechanical Sciences, vol. 30, no. 6, pp. 441-447, 1988.

[10] S. N. Shukla, Handbook for Design of Slabs by Yield-line and Strip Methods, Structural Engineering Research Centre, Roorkee, India, 1973.

[11] W. L. Gamble, "Moments in beam supported slabs," ACI Journal Proceedings, vol. 69, no. 3, pp. 149-157, 1972.

[12] R. Park, "Further test on a reinforced concrete floor designed by limit procedures in cracking, deflection and ultimate load of concrete slab systems," ACI SP-30, pp. 251-269, American Concrete Institute, Detroit, Mich, USA, 1971.

[13] W. L. Gamble, M. A. Sozen, and C. P. Siess, "Tests of a twoway reinforced concrete slabs," Journal of Structure Division, vol. 195, no. 6, pp. 1073-1096, 1969.

[14] R. Park, "Limit design of beams for two-way reinforced concrete slabs," Journal of Institution of Structure Engineers, vol. 46, no. 9, pp. 269-274, 1968.

[15] L. L. Jones and R. H. Wood, Yield-Line Analysis of Slabs, Thames and Hudson, London, UK, 1967.

[16] L. L. Jones, Ultimate Load Analysis of Reinforced and Prestressed Concrete Structures, Chatto and Windus, London, UK, 1967.

[17] M. A. Sozen and C. P. Siess, "Investigation of multi-panel reinforced concrete floor slabs: design methods-their evolutions and comparison," ACI Journal Proceedings, vol. 60, pp. 9991028, 1963.

[18] American Concrete Institute, "Building Code Requirements for Reinforced Concrete," Tech. Rep. ACI Standard 318, American Concrete Institute, Detroit, Mich, USA, 2008.

[19] British Standards, "Design of Concrete Structures. General rules and rules for buildings, Eurocode 2," Tech. Rep. BS EN1992-1, British Standards, 2008.
[20] Bureau of Indian Standards, "Code of Practice for the Design of Reinforced Concrete Structures," Tech. Rep. BIS IS 456, Bureau of Indian Standards, India, 2000.

[21] Canadian Standards Association, "Design of concrete structures," Tech. Rep. CSA Standard A23.3, Canadian Standards Association, Ontario, Canada, 1994.

[22] R. Park and W. L. Gamble, Reinforced Concrete Slabs, John Wiley and Sons, New York, NY, USA, 2000.

[23] R. H. Wood, Plastic and Elastic Design of Slabs and Plates, Thames and Hudson, London, UK, 1961.

[24] S. P. Timoshenko and S. W. Krieger, Theory of Plates and Shells, McGraw-Hill Book Company, New Delhi, India, 1959.

[25] H. Singh, M. Kumar, and N. Kwatra, "Behavior of shallowbeam supported reinforced concrete rectangular slabs: analytical and experimental investigations," Advances in Structural Engineering, vol. 13, no. 6, pp. 1183-1198, 2010.

[26] K. W. Johansen, Yield Line Theory, , Cement and Concrete Association, London, UK, 1967.

[27] A. Jennings, "On the identification of yield-line collapse mechanisms," Engineering Structures, vol. 18, no. 4, pp. 332337, 1996.

[28] S. R. Denton, "Compatibility requirements for yield-line mechanisms," International Journal of Solids and Structures, vol. 38, no. 18, pp. 3099-3109, 2001.

[29] V. Quintas, "Two main methods for yield line analysis of slabs," Journal of Engineering Mechanics, vol. 129, no. 2, pp. 223-231, 2003.

[30] H. Singh, "Laterally loaded reinforced concrete stiffenedplates: analytical investigations," Practice Periodical on Structural Design and Construction, vol. 17, no. 1, pp. 21-29, 2012.

[31] J. R. Nichols, "Statical limitations upon the steel requirement in reinforced concrete flat slab floors," Transactions of the American Society of Civil Engineers, vol. 77, pp. 1670-1736, 1914. 

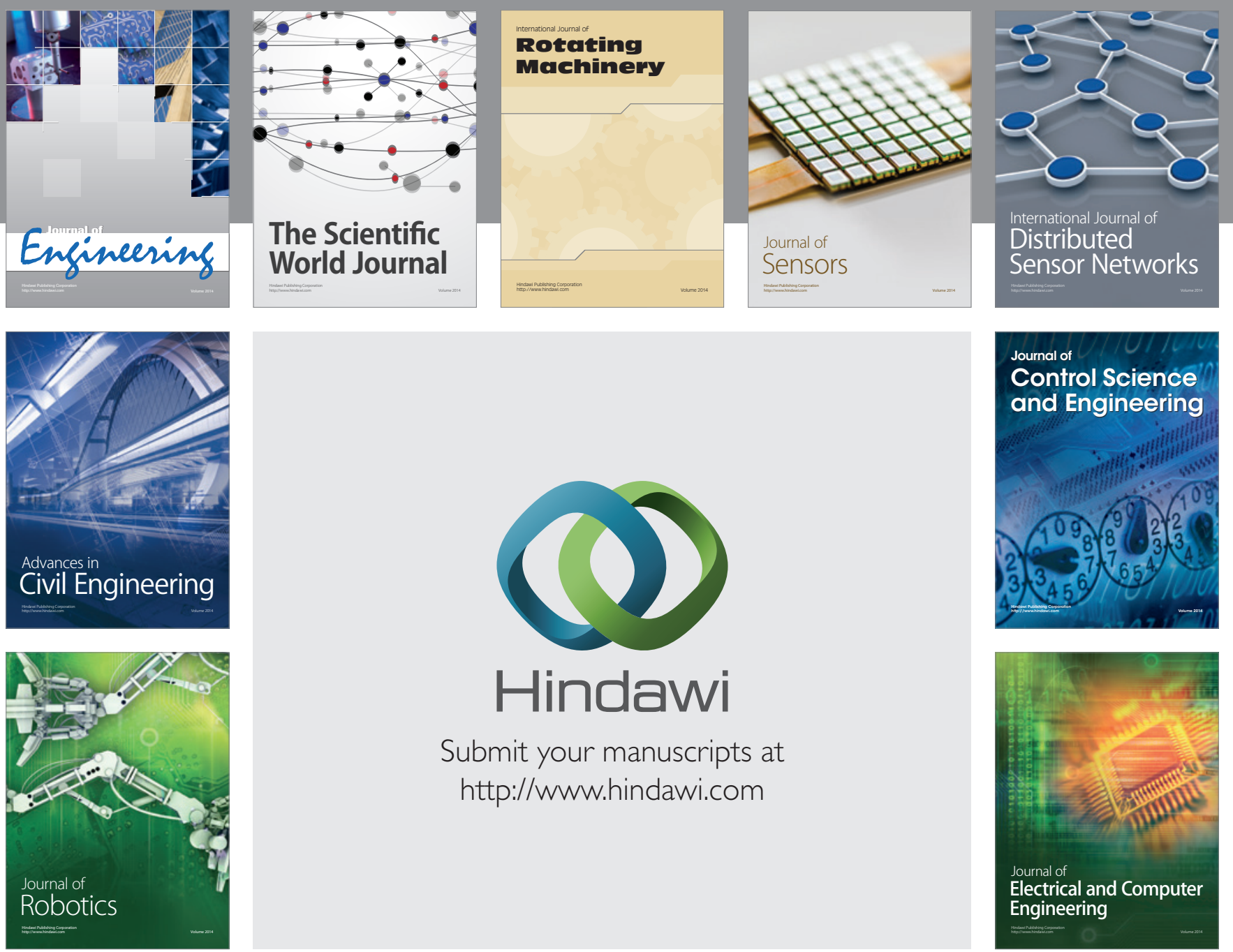

Submit your manuscripts at

http://www.hindawi.com
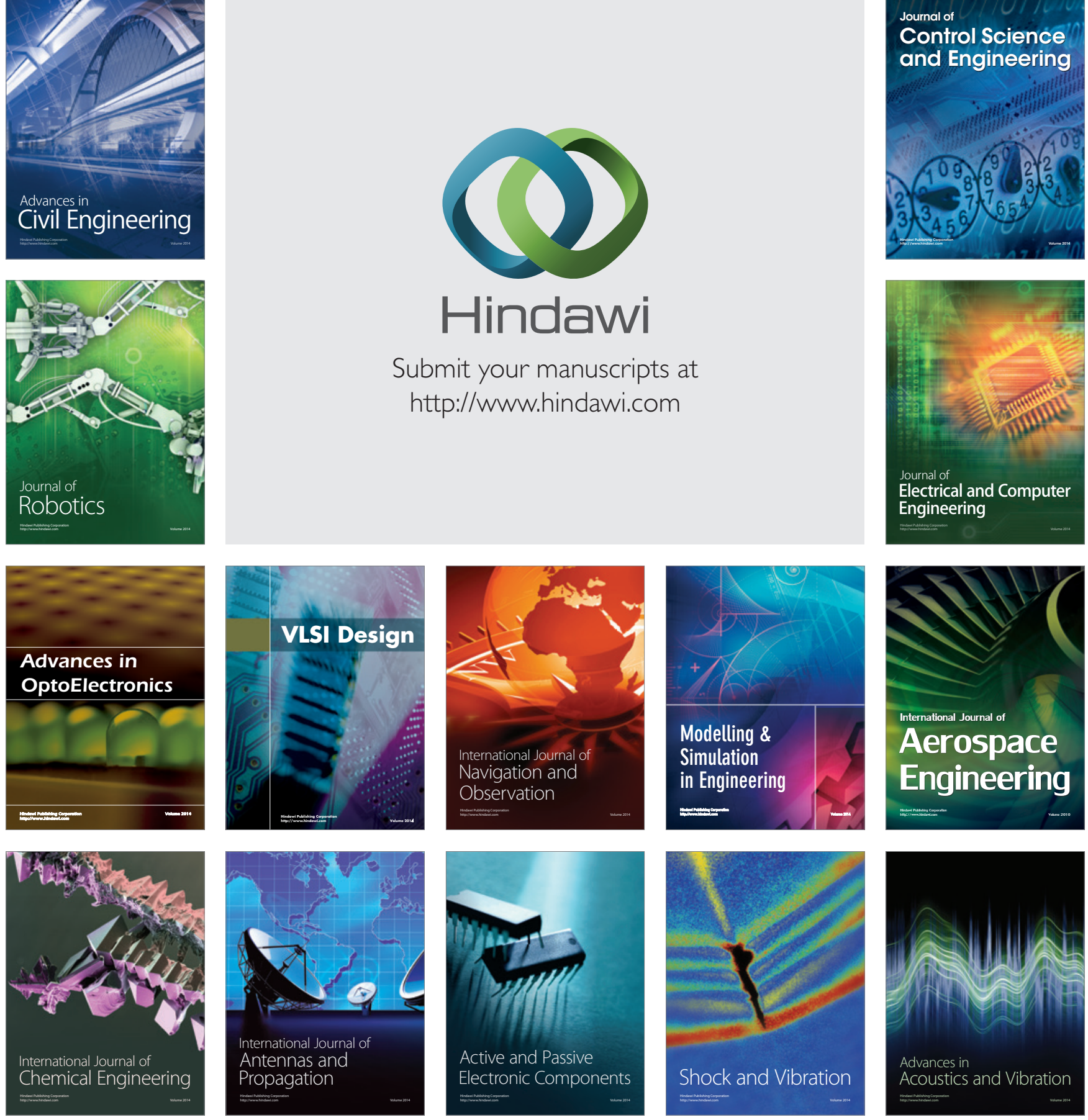